Krisztina Gracza

\title{
Pro Nederlandistica Hungariae onderscheiding voor Judit Gera
}

Prof. dr. Judit Gera, de grondlegger en meest vooraanstaande figuur van de neerlandistiek in Hongarije is voor haar levenswerk beloond met de onderscheiding Pro Nederlandistica Hungariae; in het voorjaar van 2019 heeft ze deze onderscheiding uit waardering voor haar werk in ontvangst genomen.

De onderscheiding Pro Nederlandistica Hungariae werd in 2018 op initiatief van twee Hongaarse neerlandici, Orsolya Réthelyi, hoofd van de vakgroep neerlandistiek aan de ELTE in Boedapest en Gábor Pusztai, hoofd van de vakgroep neerlandistiek aan de Universiteit Debrecen opgericht. Deze onderscheiding is bedoeld voor mensen die door de decennia heen een buitengewone prestatie hebben geleverd op het gebied van de Nederlandse taal, cultuur en literatuur in Hongarije en die hiermee wezenlijk hebben bijgedragen aan de culturele verstandhouding tussen de $\mathrm{Ne}$ derlandstalige landen en Hongarije. De prijs wordt om de twee jaar uitgereikt op basis van het oordeel van een adviescommissie van de stichting Pro Nederlandistica.

In de laudatio werden de verdiensten en werkzaamheden van Judit Gera geprezen waarvan in de volgende alinea's - vanwege de beperkte ruimte - maar een deel wordt aangehaald:

Judit Gera studeerde Hongaars en Engels, en later ook Nederlands aan de Eötvös Loránd Universiteit (ELTE) te Boedapest. Vanaf de late jaren ze- 
ventig vertaalde ze literaire werken en wetenschappelijke teksten voornamelijk uit het Nederlands. In 1982 werd ze door het hoofd van het Instituut voor Germanistiek gevraagd om aan de ELTE literatuur te doceren aan studenten Nederlands. In 1991 promoveerde ze op Van de koele meren des Doods van Frederik van Eeden. In 2000 verdedigde ze haar habilitatie waarvan de resultaten nog in hetzelfde jaar werden gepubliceerd. Ze werd in 2005 tot hoogleraar benoemd. Gedurende 23 jaar, van 1995 tot 2018 was ze vakgroephoofd van de Vakgroep Nederlands aan de ELTE.

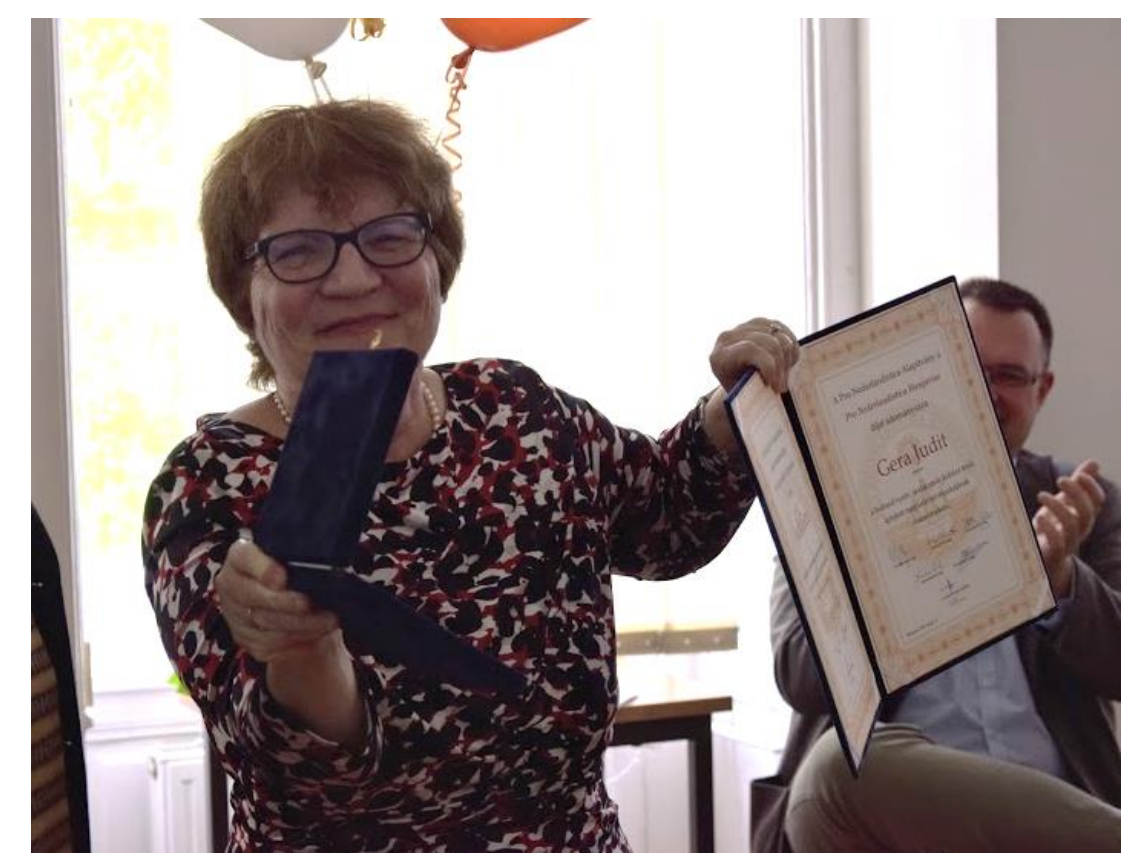

Judit Gera met haar onderscheiding.

Judit Gera heeft uitgebreid onderzoek verricht op het gebied van Nederlandstalige cultuur. De focus van haar belangstelling ligt op moderne literatuur. Ze leidde vier succesvolle onderzoeksprojecten, die in verschillende monografieën, bundels en studieboeken resulteerden. Veel van haar onderzoeks- en onderwijsactiviteiten staan in het teken van ideologiekritiek. In 2001 verscheen haar boek Van een afstand. Multatuli's Max Havelaar tegendraads gelezen. In 2012 werden haar artikelen gebundeld in haar boek, De structuren van onderwerping. Kritische studies dat in 
2016 ook in het Engels gepubliceerd is onder de titel Structures of Subjugation in Dutch Literature. Daarnaast zijn honderden artikelen, studies, kritieken, recensies en geredigeerde werken door haar gepubliceerd zowel in Hongarije als in het buitenland. Momenteel werkt ze samen met haar collega's aan de ELTE aan het schrijven van een grootschalige Hongaarse literatuurgeschiedenis, in samenwerking met de andere twee vakgroepen Nederlands in Hongarije. Dit project wordt ondersteund door de Nederlandse Taalunie. Ze was ook een actieve deelnemer aan de verschillende internationale onderzoekprojecten, die de verspreiding van Nederlandse literatuur onderzochten. Het NWO-FWO project Eastbound CODL ondersteunt ze als wetenschappelijk adviseur.

Een belangrijk deel van het onderzoek van Judit Gera is rechtstreeks gerelateerd aan het onderwijs. Het meest sprekende voorbeeld hiervan is het handboek Inleiding literatuurgeschiedenis voor de internationale neerlandistiek dat ze schreef in samenwerking met haar vriend en collega dr. A. Agnes Sneller, voormalig hoogleraar aan de Károli Protestantse Universiteit. Haar onderwijsactiviteiten hebben de neerlandistiek in Hongarije in belangrijke mate gevormd: de meeste docenten die nu aan de verschillende vakgroepen Nederlands les geven, zijn ooit studenten van haar geweest. Als lid van de Doctorale School van Literatuur aan de ELTE heeft ze vier PhD studenten begeleid. Veel van haar studenten hebben later werk gevonden in de particuliere sector, een aantal oudstudenten hebben in Nederland en België doorgestudeerd of daar werk gevonden. Al deze mensen zijn verbonden door de instelling van de Vakgroep Nederlands aan de ELTE: openheid, hoge eisen, een kritische houding en diepe interesse in de cultuur van de Lage Landen. Bij het tot stand komen en de verspreiding van deze instelling speelde en speelt Judit Gera nog steeds een beslissende rol.

Judit Gera is ook een van de meest productieve literair vertalers van Hongarije. Haar oeuvre als literair vertaler werd in 2001 door het Koninkrijk der Nederlanden met de Martinus Nijhoff-prijs erkend. In 1999 is ze onderscheiden als Ridder in de Orde van Oranje-Nassau voor de verspreiding en promotie van de Nederlandse cultuur in Hongarije. Ze is lid van de Maatschappij der Nederlandse Letterkunde en zit in de redactie van verschillende vaktijdschriften. 


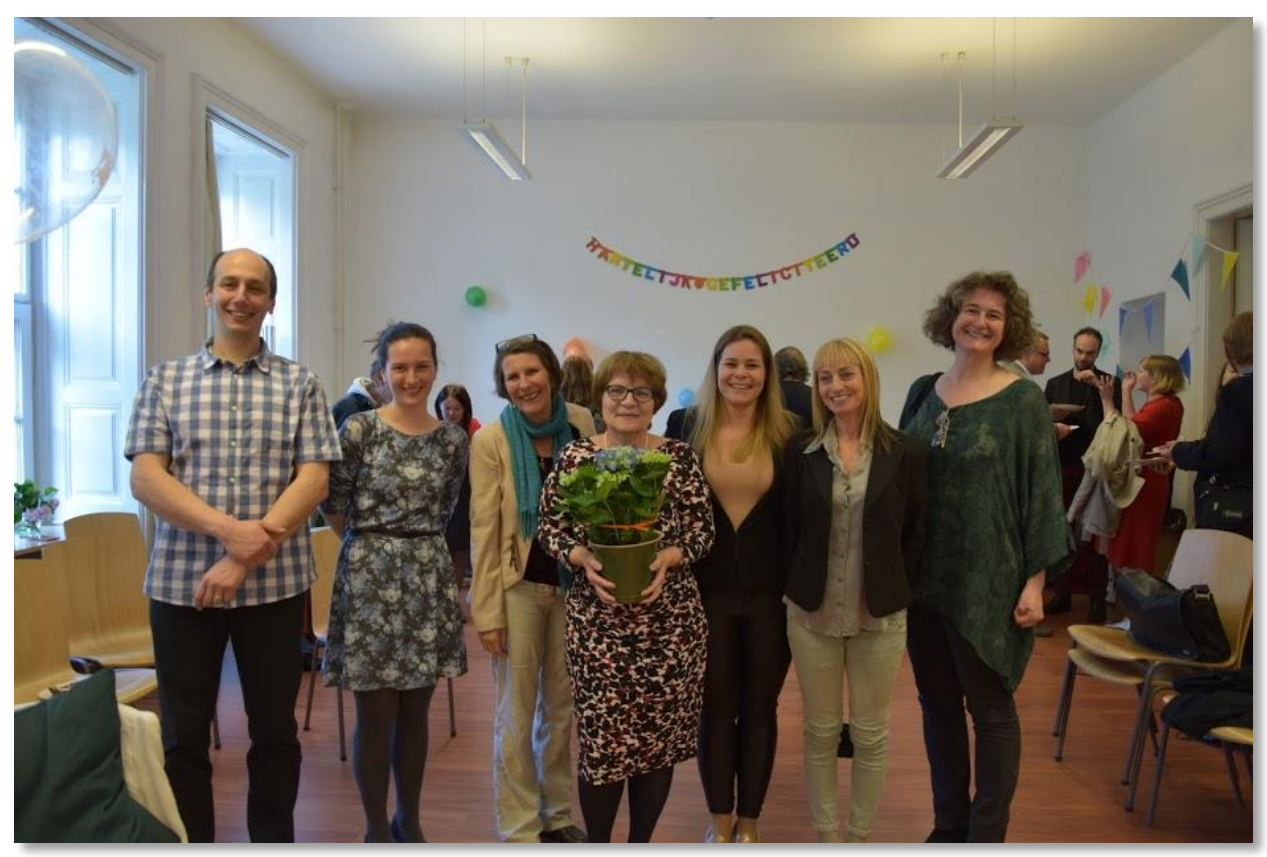

Judit Gera (midden) met de medewerkers van de Vakgroep Neerlandistiek van de ELTE: Roland Nagy, Krisztina Gracza, Martine Bijvoet, Janina Vesztergom, Orsolya Varga en Orsolya Réthelyi

De feestelijke toekenning van haar meest recente erkenning, de onderscheiding Pro Nederlandistica Hungariae werd ter gelegenheid van de viering van haar verjaardag aan haar uitgereikt. Nietsvermoedend stapte Judit Gera op 17 mei 2019 een gewoon klaslokaal aan de universiteit binnen waar tientallen collega's, vrienden en studenten in het geheim op haar zaten te wachten. Na het welkomstwoord van Orsolya Réthelyi vond de feestelijke toekenning van de onderscheiding plaats: Gábor Pusztai las de laudatio in twee talen voor en hij overhandigde de onderscheiding aan Judit Gera. Hierna kwam een lange rij aan felicitaties waarvan het bijzondere was dat het zowel persoonlijk als virtueel gebeurde. De persoonlijke toespraken werden door René van Hell, ambassadeur Koninkrijk der Nederlanden en David Maenaut, Algemeen Afgevaardigde van de Vlaamse Regering geopend en werden gevolgd door felicitaties en warme wensen van het hoofd van het Instituut voor Germanistiek ELTE (Roberta Rada), van collega's (Anikó Daróczi, Károly Manherz, Ádám Nádasdy), vrienden (Antje Koelewijn) en (oud)studenten. Elke persoonlijke gelukwens 
werd door een videoboodschap gevolgd van mensen die niet de mogelijkheid hadden om voor het feest naar Boedapest te komen. Zo kon onder andere Abdelkader Benali, Elke Brems, Marc le Clercq, Ingrid Degraeve, Małgorzata Dowlaszewicz, Ton van Kalmthout, Tom Lanoye, Anton van der Lem, Maaike Meijer, Joseph Pearce, Thomas Rosenboom en Erika Winkler de jarige virtueel feliciteren. Daarnaast hebben collega's van de vakgroep met een muzikaal programma Judit Gera gevierd. Het feest werd door een gezellige borrel met champagne en zelfgemaakte taarten afgesloten. 